disciplines, and also, let it be said, the finances which made long-term intensive studies possible. We used to see more animals, but it was an experience impoverished in some degree, by ignorance. This ignorance Cynthia Ross clearly sees as a challenge to be met.

JOHN OWEN

\title{
Fallow Deer, by Donald and Norma Chapman. Terence Dalton, $\mathfrak{£} 7.80$.
}

This is a very readable and comprehensive review of fallow deer history, distribution and biology. In addition to the inevitable chapters on classification, anatomy, antlers, reproduction, social organisation and behaviour, ecology and mortality, there is an exhaustive examination of the fossil and early history of the fallow deer (including that hoary topic of who actually introduced it to Britain) and a concluding chapter on the Persian fallow deer to delight the international conservationist. The book is not only profusely but also sensibly illustrated, in that most of the plates depict, very clearly, anatomical and other features referred to in the text.

Fallow must be one of the most widely introduced deer in the world, and the chapter on distribution traces the species's past and present whereabouts over the five major continents. The subject is a dynamic one. A recent report to IUCN suggests that the fallow deer in Sardinia may already be extinct. On the cther side of the coin, a recent fallow-deer survey in Turkey has identified a third population in an area north of Adana that has been accorded reserve status.

The authors endeavour to define and to identify the causes of fraying and thrashing (the term they use) of vegetation by bucks in antler. But the text and accompanying illustrations suggest that they still haven't got it quite right! If similar behaviour in red deer is any indication, the damage to the saplings shown in the plate on page 129 was not caused by fraying (the deer would never use trees of such large diameters for this purpose), but by body rubbing, principally of the face and neck, in which antler scores on the bark are apparently incidental. The suggestion that a great deal of thrashing occurs long after the rut is certainly confirmed by red deer behaviour in the eastern Scottish highlands.

The chapter on ecology gives lucid and convincing arguments on the need for sound deer management, and the authors have clearly scoured the literature to provide a useful review of the causes of mortality and the diseases and parasites that afflict fallow deer. All in all, they are to be congratulated on having brought together a considerable and wide range of information.

COLIN W. HOLLOWAY

\section{Collins Encyclopaedia of Animals. Introduction by Desmond Morris. Collins, $£ 15$.}

This magnificent volume of 640 pages is based on La Vie des Animaux, published by La Librairie Larousse in 1969. The text has been contributed by fifteen of France's most distinguished zoologists under the guidance of Pierre-Paul Grasse, member of the French Institute. The present edition has been adapted for an English-speaking readership with the help of $A$. $R$. Waterston, Keeper Emeritus of Natural History at the Royal Scottish Museum, Edinburgh.

This is in the true sense an encyclopaedia, and not merely the alphabetical catalogue of animals that sometimes appears under such a title. The animal groups are dealt with in a systematic order, starting with unicellular organisms and proceeding through the natural subdivisions of the animal world to the primates. In each group structure, classification, habitat, life-cycles and in most cases distribution are dealt with, and where appropriate topics such as dimorphism, parasitism, mimicry, defensive mechanisms and behaviour are discussed in some detail. For the general reader one would have liked to see more indications of species on the endangered list. As might be expected of such a team of authors, the text is authoritative and up-to-date but written in a pleasant discursive style, as clear of technical 